\title{
A Comparative Performance Analysis of Counter-Rotating Dual-Rotor Wind Turbines with Speed-Adding Increasers
}

\author{
Radu Saulescu $^{1}$ D, Mircea Neagoe ${ }^{2, *(\mathbb{D})}$, Codruta Jaliu $^{2}$ and Olimpiu Munteanu ${ }^{2}$ \\ 1 Design of Mechanical Elements and Systems R\&D Centre, Transilvania University of Brasov, \\ 500036 Brasov, Romania; rsaulescu@unitbv.ro \\ 2 Renewable Energy Systems and Recycling R\&D Centre, Transilvania University of Brasov, \\ 500036 Brasov, Romania; cjaliu@unitbv.ro (C.J.); omunt@unitbv.ro (O.M.) \\ * Correspondence: mneagoe@unitbv.ro; Tel.: +40-268-413-000
}

Citation: Saulescu, R.; Neagoe, M.; Jaliu, C.; Munteanu, O. A Comparative Performance Analysis of Counter-Rotating Dual-Rotor Wind Turbines with Speed-Adding Increasers. Energies 2021, 14, 2594. https: / / doi.org/10.3390/ en14092594

Academic Editor: Andrzej Bielecki

Received: 29 March 2021

Accepted: 28 April 2021

Published: 1 May 2021

Publisher's Note: MDPI stays neutral with regard to jurisdictional claims in published maps and institutional affiliations.

Copyright: (c) 2021 by the authors. Licensee MDPI, Basel, Switzerland. This article is an open access article distributed under the terms and conditions of the Creative Commons Attribution (CC BY) license (https:// creativecommons.org/licenses/by/ $4.0 /)$.

\begin{abstract}
Increasing the efficiency of wind power conversion into electricity poses major challenges to researchers and developers of wind turbines, who are striving for new solutions that can ensure better use of local wind potential in terms of both feasibility and affordability. The paper proposes a novel concept of wind systems with counter-rotating wind rotors that can integrate either conventional or counter-rotating electric generators, by means of the same differential planetary speed increaser, aiming at providing a comparative analysis of the energy performance of counter-rotating wind turbines with counter-rotating vs. conventional electric generators. To this end, a generalized analytical model for angular speeds and torques has been developed, which can be customized for both system configurations. Three numerical simulation scenarios have been contrasted: (a) a scenario with identical wind rotors in both systems, (b) a scenario with the secondary wind rotors being identical in the two applications, but different from the primary rotors, and (c) a scenario with different secondary rotors in the two wind turbines. The results have shown that the wind systems with counter-rotating generator are more efficient and have a higher amplification ratio, compared to systems with conventional generators. In addition, the analyzed wind system with a counter-rotating generator displays better energy performance with low values for output power and ratio of input speeds, whereas the wind turbine with a conventional generator proves to be more efficient in the high-value range of the above-mentioned parameters.
\end{abstract}

Keywords: wind turbine; counter-rotating wind rotors; counter-rotating electric generator; planetary speed increaser; speed-adding increaser; modeling; operational point

\section{Introduction}

Wind energy has become increasingly popular among renewable energy sources worldwide, representing a valuable alternative to fossil fuels and other polluting sources of energy production. Most of the wind turbines that are currently in operation both onshore and offshore have a conventional structure, consisting of a single wind rotor, a speed increaser and a conventional generator. However, as the use of wind energy is gathering pace, there is a constant need for either improving the existing wind turbines or developing innovative higher performance models. Thus, a better use of wind potential and a more efficient energy conversion, leading to a boost in electricity production, are major milestones that researchers, designers and developers in the field are constantly striving to reach.

In recent years, several innovative wind turbine solutions have been developed with improvements regarding the wind rotor, the speed increaser or the electric generator. For instance, a number of studies have been conducted on various issues, such as:

- the development of innovative concepts of wind turbines (with horizontal axis and counter-rotating rotors [1-4], or with multiple and smaller rotors in a spatial arrangement [5]). An example of comprehensive, but not exhaustive overview of research 
achievements in counter-rotating wind turbine systems development, characterization and use can be found in [4];

- the influence of rotor pitch on the output power of a conventional wind turbine [6] and of a counter-rotating wind turbine [7];

- the effect of the number of blades of counter-rotating wind turbines on the system performance [8];

- the performance of new types of counter-rotating wind turbine with vertical axis [9,10], etc.

Several studies have offered a contrastive approach to single-rotor vs. counter-rotating wind turbines, proving that the latter can increase the power conversion efficiency by $40 \%$ as against the former [7,11]. When using the two types of rotor in wind farms, Vasel-BeHagh et al. concluded that the use of a counter-rotating configuration leads to $22.6 \%$ more power than in the case of single-rotor wind turbines [11].

Wind turbines usually include a speed increaser, whose function is to transmit mechanical energy, as well as to boost the lower speed of wind rotors so that the electric generator's speed requirement be met. Research on speed increasers has covered various topics, such as: the fixed-axis gearbox type [12-14], planetary transmissions [5,15-19] or variable transmissions [20-22], analyzed as part of single-rotor wind turbines or counterrotating systems, by e.g., the structure of an improved wind turbine gearbox is presented for meeting the operation of the optimized wind turbine power-wind speed curve [22].

The planetary speed increaser type is mainly used in high-power conventional wind systems and in counter-rotating turbines, due to their advantages: high amplification ratios, reduced radial sizes and better efficiency [1,3,16,17,23-32]. With dual-rotor systems, the speed increaser, operating as a 2-DOF transmission, sums up the rotors' input speeds [26,30], while operating as a 1-DOF planetary transmission, it sums up the rotors' input torques [31-33]. Qiu et al. proposed in [23] a synthesis of planetary speed increasers mainly for high-power wind turbines, considering both 1-DOF and 2-DOF types.

A dynamic response of a wind turbine gearbox under different excitation conditions is reported in [34] by Zhao and Ji, while Dong et al. used a similar approach and investigated the dynamics of a planetary transmission for wind turbines that influences the conversion efficiency and proves that the use of a planetary gear train is the best option for wind turbines [35]. Vázquez-Hernández C. et al. analyzed in [36] different gearbox arrangements for onshore wind turbines, as well as the factors that affect their design, proving that the current trend in the market is to use planetary transmissions rather than gearless wind turbines. Farahani et al. [37] evaluated and compared the transient performance of the single-rotor and the counter-rotating wind turbines, concluding that performance would be enhanced by using the second type.

Recently, new developments in electric generators for wind turbines have been presented in the specialist literature, many of which are in the prototype phase. For example, an axial-flux generator with a counter-rotating field and armature for counter-rotating wind turbines is proposed and analyzed by Kutt et al. in [38], but the solution has proven to have low efficiency; a permanent magnet synchronous generator with mobile armatures (both stator and rotor) is put forth in various studies [32,39-42], the innovative design being proposed for low-power applications. Still, research in this area has shown that the use of counter-rotating (with mobile stator) - instead of conventional (with fixed stator) - electric generators can provide additional energy gain.

Combining the previous concepts, Pacholczyk et al. [43] proposed a small counterrotating wind turbine consisting of two counter-rotating rotors, a 1-DOF planetary gearbox and counter-rotating generator. The authors investigated its performance and operational point as functions of axial distance and tip speed ratio of each rotor. Another study on the comparative behavior of a single-rotor wind turbine with 1-DOF planetary speed increaser and counter-rotating vs. conventional electric generator was reported by Saulescu et al. in [44]. The operating point was derived by reducing the mechanical characteristic of the wind rotor at the shaft of the electric generator rotor. Numerical simulations highlighted higher efficiency for systems with parallel flow of mechanical power. However, in both 
studies, authors presented a particular configuration of wind turbine- the model not being generalized. Other approaches can be find in [45] and [46], where Fan et al. and Hong and Fan, respectively, utilise the empirical mode decomposition method and the particle swarm optimization algorithm, who have been successfully hybridized with the support vector regression to produce satisfactory forecasting performance. A review of the performance and reliability of wind turbines is done by Pfaffel et al. in [47].

The foregoing brief survey of specialist literature reveals that a relatively small number of studies have contrasted only particular configurations of counter-rotating wind turbines. However, they do not report generalized analytical models that can be customized to different operational cases of wind turbines. This paper aims to bridge the gap and proposes a novel concept of a counter-rotating wind system that can integrate one of the two types of electric generator and uses the same 2-DOF planetary speed increaser. The goal is to compare the energy performance of counter-rotating wind turbines with a counter-rotating vs. conventional electric generator. To this end, a generalized analytical model for angular speeds and torques is developed, which can be customized for both system configurations and which allows to obtain the operational point of the two types of wind turbine. Three numerical simulation scenarios will be considered: (a) a scenario with identical wind rotors in both systems, (b) a scenario with the secondary wind rotors being identical in the two applications, but different from the primary rotors, and (c) a scenario with different secondary rotors in the two wind turbines-where the mechanical characteristics are obtained from the condition of achieving the same ratio between the input angular speeds of both wind systems. Thus, the influence of mechanical characteristics on the behavior of the considered wind systems can be identified. The results of this comparative study will confirm the acknowledged conclusion that the counter-rotating type is more efficient, and they will also allow to define the extent to which performance of wind systems with a counter-rotating generator exceeds that of conventional generator applications.

Subsequent to these introductory, general considerations, the paper has the following structure: Section 2, in which two configurations are proposed of counter-rotating wind turbines consisting of two counter-rotating rotors, a speed increaser that can function as a 2 in-1 out or 2 in- 2 out transmission, and either a conventional or counter-rotating electric generator; Section 3, in which a generalized analytical model is presented for angular speeds, torques, efficiency and operational point with both configurations; Section 4, in which numerical simulations and analyses are performed for the three scenarios; and Section 5, which provides final conclusions.

The main contributions of this paper to the scientific endeavor in the field are: a novel concept of a counter-rotating wind system using the same differential planetary speed increaser and either counter-rotating or conventional electric generator; a generalized close-form model of 2-DOF wind systems which can be used, by customization, for performance investigation of both types of wind turbine (with a counter rotating vs. conventional electric generator); three numerical simulation scenarios performed and analyzed comparatively, aiming to identify performance of each type of wind turbine in relation to relevant input parameters.

\section{Problem Formulation}

The in-parallel transmission of mechanical power from inputs to outputs can be achieved by power split at input, output or both, which ensures a higher efficiency compared to transmissions obtained by serial connection of the same component mechanisms [48]. A new approach to the development of modern wind turbines is the use of two counter-rotating coaxial rotors and the integration of a counter-rotating electric generator, which requires a mechanical transmission with power split at both input and output.

In order to identify the energy gain brought by a counter-rotating electric generator as against a conventional, fixed-stator generator, the paper presents a comparative study of two wind turbines having the same components (wind rotors, speed increaser and electric generator), so that the reference wind system (with a conventional generator) is derived from the wind system with two inputs and two outputs as a particular case, by releasing 
the stator of the electric generator and fixing it to the frame. Thus, the general case is considered of a wind turbine with two counter-rotating rotors $R 1$ and $R 2$, a 2-DOF speed increaser (SI), and an electric generator consisting of either a mobile rotor $G R$ and a mobile stator GS (in the case of a counter-rotating generator, the 2 in- 2 out wind system type shown in Figure 1a) or a fixed stator (conventional generator GS $\equiv 0$, the 2 in- 1 out wind system type shown in Figure 1b). In order to ensure equivalence of the two wind systems under comparative analysis, the following hypotheses are considered:

- The same set of rotors $R 1$ and $R 2$ is used in both wind systems and the same set of mechanical characteristics is considered in modeling these systems, implicitly. Conventionally, $R 1$ is the primary wind rotor and $R 2$ - the secondary rotor. The mechanical characteristics of wind turbines can be considered as linear functions with constant coefficients in operation at a constant wind speed. However, the values of these coefficients depend on both the value of wind speed and the characteristics of wind rotor, e.g., the pitch angle of blades.

- In both cases, the speed increaser SI has the same structure and the same values for internal kinematic ratio $i_{0}$ and internal efficiency $\eta_{0}$ [49]. The mechanical transmission is a differential mechanism (2-DOF) with two inputs that are connected to wind rotors $R 1$ and $R 2$, and one or two outputs, through which the mechanical power is transmitted either to rotor GR of the conventional generator or to rotor GR and stator GS of the counter-rotating generator.

- The counter-rotating electric generator is obtained from the conventional one, by setting the stator GS to rotate in opposite direction to the rotor GR; the two generators have the same mechanical characteristics with respect to the relative speed of rotor $G R$ and stator $G S$, i.e., $\omega_{G}=\omega_{G R}-\omega_{G S}$. For the sake of simplicity, the case of direct current $(D C)$ generators is further considered, which are characterized by linear mechanical characteristics with constant coefficients, is further considered.

- The ratio of angular speeds of wind rotors is denoted by $k_{\omega}=-\omega_{R 2} / \omega_{R 1}>0$. The ratio $k_{\omega}$ can be adjusted during wind turbine operation by changing the pitch angle of the two rotors $R 1$ and $R 2$, which also changes their mechanical characteristics.

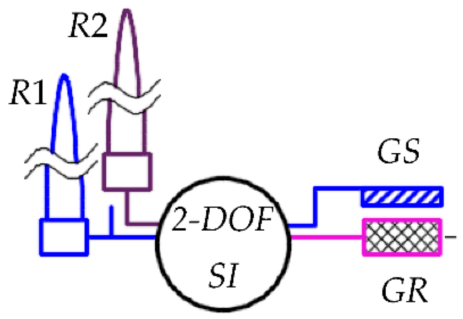

(a)

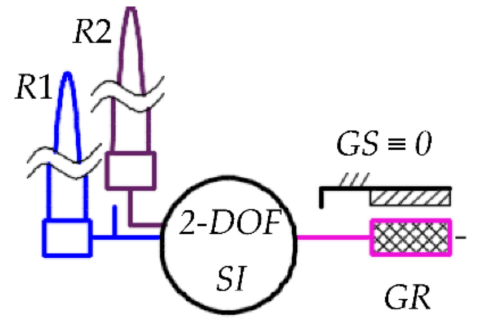

(b)

Figure 1. Block diagrams of the differential counter-rotating wind systems that are considered in the comparative analysis: (a) with counter-rotating generator; (b) with conventional generator.

The proposed mathematical model of a wind system with a counter-rotating generator, under the above-mentioned hypotheses, also allows for the description of the system with a conventional electric generator by customizing the state of stator GS: the stator is fixed to the frame after disconnecting it from the speed increaser (see Figure 1).

The case of a planetary speed increaser with cylindrical gears and single serial satellite gears-illustrated in Figure 2 below only through its upper half-is further used to exemplify the mathematical modeling and to identify the relevant properties by numerical simulation of the two wind systems. This transmission consists of two sun gears 1 and 4, meshing with two or more sets of serial satellites 2-3 that are articulated through revolute joints to a satellite carrier $H$. The speed increaser has two inputs, carrier $H$ and gear 4 , which are connected to primary wind rotor $R 1$ and secondary wind rotor $R 2$, respectively, and which 
can operate with either two outputs ( 1 and $H$, Figure $2 a)$ or a single output (1, Figure $2 b$ ). The main output is through gear 1 , which is connected to rotor $G R$, while, in the case of the counter-rotating generator, the secondary output $H$ is held fixed to stator GS. As a result, the analyzed planetary transmission has either $L=4$ (Figure 2a) or $L=3$ (Figure 2b) external connections, two degrees of freedom $(M=2)$ and, therefore, two independent external speeds $\left(\omega_{H}\right.$ and $\left.\omega_{4}\right)$, as sun gear 1 , ring gear 4 and carrier $H$ are mobile bodies.

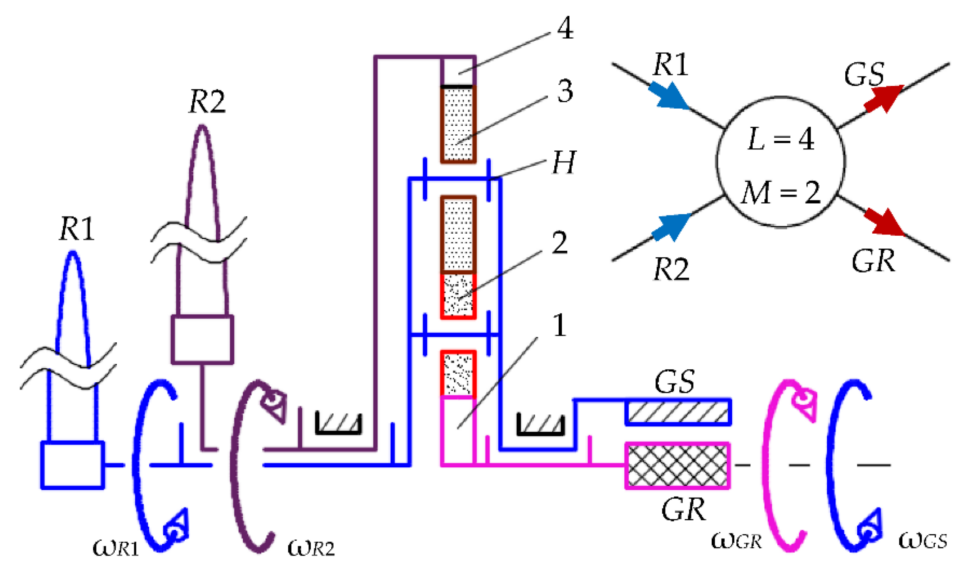

(a)

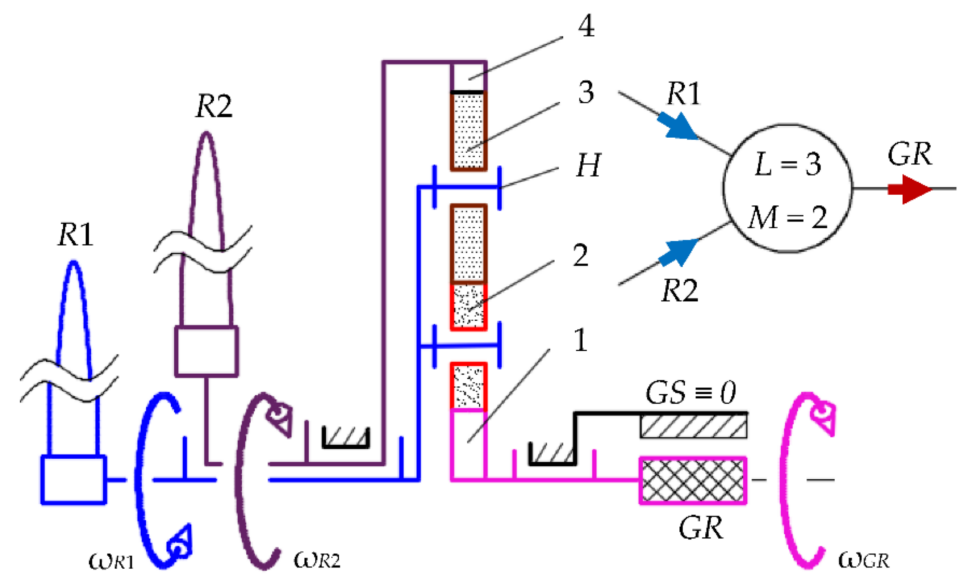

(b)

Figure 2. Structural and block diagrams for wind systems with two counter-rotating inputs, a differential planetary speed increaser and: (a) counter-rotating generator; (b) conventional generator.

Wind rotors $R 1$ and $R 2$ have angular speeds $\omega_{R 1}$ and $\omega_{R 2}$ in opposite directions-a property ensured by setting opposite inclinations of the two rotors' blades. The two outputs of the speed increaser, by 1 and $H$, are also counter-rotating due to the kinematic property given by the planetary transmission structure, as highlighted in the next section. Being a differential mechanism, the speed increaser sums up the two input angular speeds $\omega_{R 1}$ and $\omega_{R 2}$ in an output angular speed $\omega_{G R}$. Angular speed $\omega_{G S}$ of stator $G S$ is identical to the input speed of primary rotor $R 1$ (Figure 2a), as a result of the direct connections GS-H-R1.

The analytic modeling of angular speed, torque, power and efficiency of the two wind systems starts from the general case of a wind turbine with a counter-rotating generator and then customized for the particular case of a system with a conventional generator. To this purpose, the kinematic and static correlations of the planetary speed increaser are established on the basis of the block diagrams shown in Figure 3 below and detailed in [33], as well as on the mechanical characteristics of the wind rotors and electric generator, considering the influence of the ratio of input speeds $k_{\omega}=-\omega_{R 2} / \omega_{R 1}$ on the behavior and performance of the two wind systems. Notations in Figure 3 are: $T_{x}$ and $\omega_{\mathrm{x}}$ for torque 
and angular speed of kinematic body $x ; i_{0}$ and $\eta_{0}$ for internal kinematic ratio and internal efficiency of the speed increaser-all of which representing the intrinsic parameters of the planetary transmission [33]. In particular, carrier $H$ is connected to primary rotor $R 1$ by $H R$ shaft and to the generator stator GS by HS shaft (see Figure 3a).

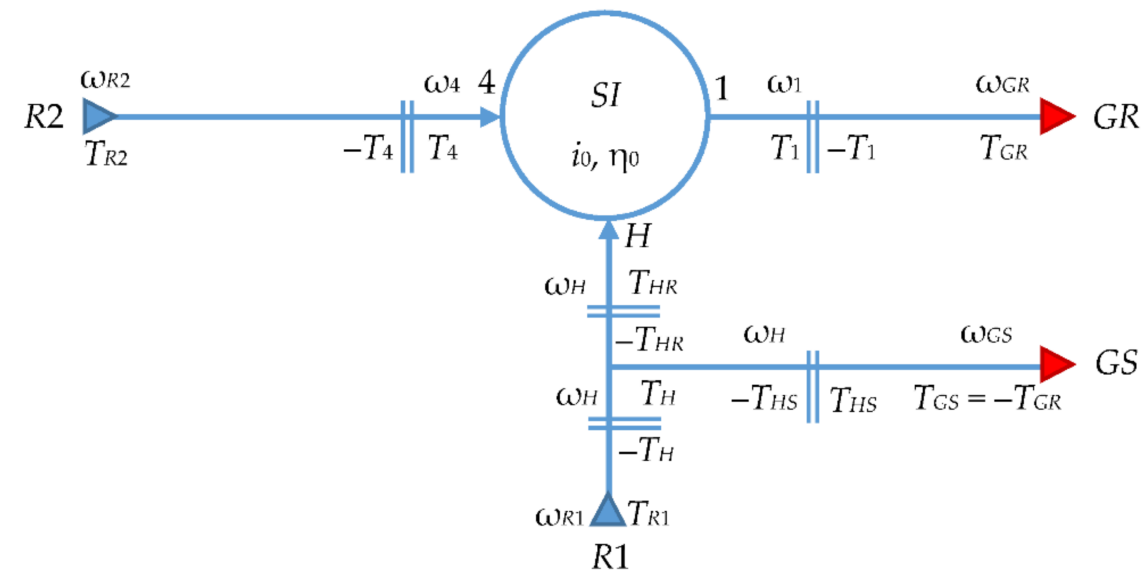

(a)

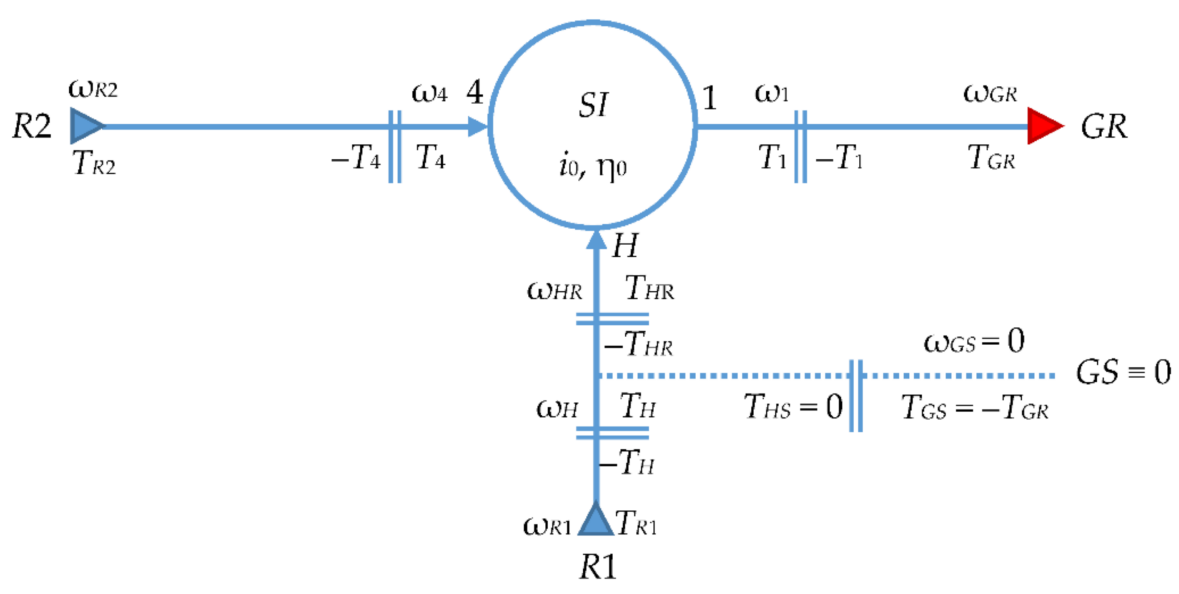

(b)

Figure 3. Block diagram of the differential wind system with two inputs and: (a) two outputs; (b) one output.

The system with conventional generator, Figure $3 b$, can be illustrated and analyzed as a particular case of the system with counter-rotating generator, Figure 3a, by disconnecting the shaft $H S$ from the carrier $H$ (i.e., $T_{H S}=0$ ) and by fixing the stator $G S$ to the frame (i.e., $\left.\omega_{G S}=0\right)$.

\section{Analytic Modeling of Wind Systems}

The mathematical modeling of the generalized counter-rotating wind turbine system (with a counter-rotating generator) is performed by applying the method of isolating the components, which involves breaking their connections and replacing them with the appropriate parameters of mechanical power transmitted through these connections. The steps of the applied algorithm for the analytical modeling of the considered wind systems (Figure 2), according to the block diagram and notations in Figure 3, are presented in the flowchart depicted in Figure 4. 
Decomposition of the wind system into components, Figure 3

C1: 2-DOF planetary speed increaser $S I\left(i_{0}, \eta_{0}\right)$;

$\mathrm{C} 2$ : primary wind rotor $\mathrm{R} 1$; $\quad \mathrm{C} 3$ : secondary wind rotor $\mathrm{R} 2$;

C4: electric generator rotor GR; $C 5$ : electric generator stator GS;

C6: intermediate shaft between $R 1, G S$ and carrier $H$.

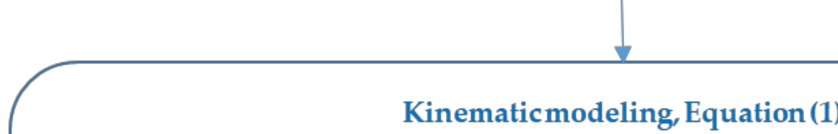

K1: angular speed transmitting function of the planetary speed increaser;

$\mathrm{K} 2$ : kinematic equations of the connections between components;

K3: kinematicratio of the input angular speeds, $k_{\omega}$, Equation (3);

Input parameters: $\omega_{R 1}$ and $k_{\omega}$.

Output parameters: $\omega_{R 2}, \omega_{G R}, \omega_{G S}, \omega_{H^{\prime}} \omega_{1}, \omega_{4^{\prime}} \omega_{G}=\omega_{G R}-\omega_{G S}$

Remark: in the particular case of the 2 in-1out system, $\omega_{G S}=0$.

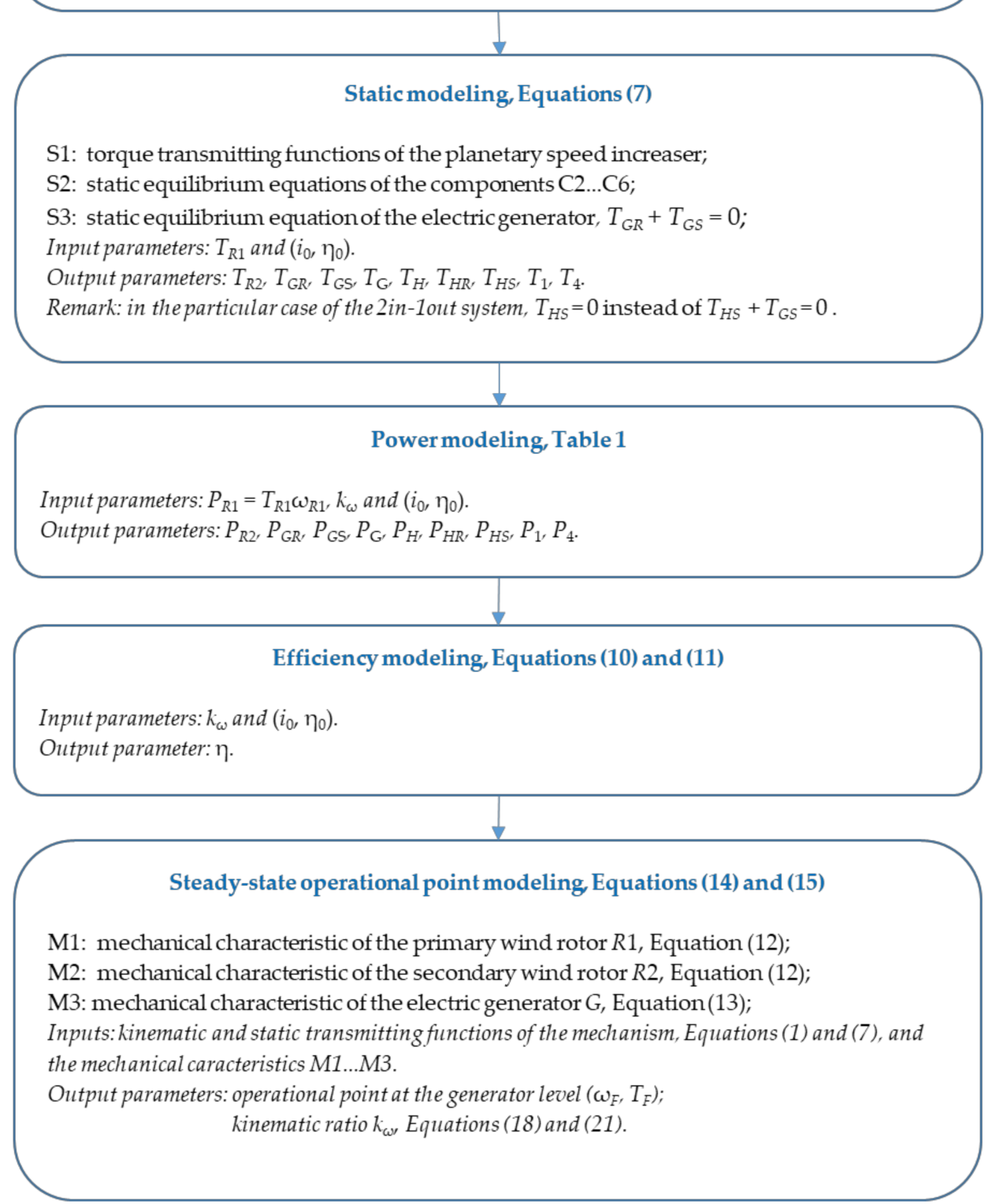

Figure 4. Algorithm for analytical modeling of the generalized 2-DOF dual-rotor counter-rotating wind systems. 


\subsection{Kinematic Modeling}

This modeling aims at establishing the relationships between the dependent angular speeds and the two independent external angular speeds of the speed increaser $\left(\omega_{H}\right.$ and $\left.\omega_{4}\right)$. For this purpose, the speed increaser is characterized by a function of transmitting angular speeds, while each connection (represented by a double line in Figure 3) between the components of the wind system is described through a distinct kinematic equation. Thus, the following system of equations can be written [33]:

$$
\left\{\begin{array}{l}
\omega_{1}=\omega_{H}\left(1-i_{0}\right)+\omega_{4} i_{0} \\
\omega_{R 1}=\omega_{H} ; \omega_{R 2}=\omega_{4} \\
\omega_{G R}=\omega_{1} ; \omega_{G S}=\omega_{H}
\end{array}\right.
$$

where the internal kinematic ratio $i_{0}$ can be calculated from the particular case when $H$ is assumed to be fix, given by relation (2):

$$
i_{0}=i_{14}^{H}=\omega_{1 H} / \omega_{4 H}=z_{4} / z_{1},
$$

where $i_{14}^{H}$-angular speed transmission ratio from gear 1 to gear 4 when carrier $H$ is considered fixed (or reference body), $\omega_{x y}$-angular speed of body $x$ relative to body $y$, $z_{j}$-the number of teeth of gear $j ; i_{0}$ is defined as the kinematic ratio of the fixed axes mechanism that is associated to the planetary gear train, being obtained by reversing the motion relative to the carrier $H$ [49].

Based on the relation between the input angular speeds, as defined by ratio $k_{\omega}$ :

$$
\omega_{R 2}=-k_{\omega} \omega_{R 1}
$$

the relative angular speed between rotor $G R$ and stator $G S$ of the electric generator, $\omega_{G}$, can be obtained:

$$
\omega_{G}=\omega_{G R}-\omega_{G S}=-\omega_{R 1} i_{0}\left(1+k_{\omega}\right) .
$$

The system of Equation (1) is equally valid for the wind turbine with one output (Figure $2 b$ ), except that the last equation has to be replaced by Equation (5):

$$
\omega_{G S}=0
$$

that characterizes the stator GS, which is fixed to the frame after disconnecting it from wind rotor $R 1$. Therefore, the relative angular speed of the electric generator becomes:

$$
\omega_{G}=\omega_{G R}=\omega_{R 1}\left[1-i_{0}\left(1+k_{\omega}\right)\right]
$$

\subsection{Torque Correlation and Efficiency Modeling}

According to the diagram in Figure 3, the wind system with counter-rotating generator is modeled by a set of 9 static equilibrium equations consisting of:

- two torque transmitting functions that are obtained from the static modeling of the differential planetary speed increaser; the number of functions is equal to the mechanism degree of freedom $(M=2)$. Additionally, the condition of static equilibrium of the planetary transmission can be added as dependent equation for verification purposes;

- a static equilibrium equation for each of the other five components of the wind system, which are obtained after breaking the connections;

- the static equilibrium equation of the electric generator, described from the condition that the torque values at rotor $G R$ and stator $G S$ are equal and in opposite direction. 
As a result, the set of equations for the differential wind system in Figure 2a-with two counter-rotating inputs and two counter-rotating outputs-can be written as follows:

$$
\left\{\begin{array}{l}
T_{H R}=-T_{1}\left(1-i_{0} \eta_{0}^{-1}\right) ; T_{4}=-T_{1} i_{0} \eta_{0}^{-1} ; T_{1}+T_{4}+T_{H R}=0 ; \\
T_{R 1}-T_{H}=0 ; T_{R 2}-T_{4}=0 ; T_{G R}-T_{1}=0 ; T_{G S}+T_{H S}=0 ; T_{H}-T_{H R}-T_{H S}=0 ; \\
T_{G}=T_{G R}=-T_{G S} ;
\end{array}\right.
$$

where the internal efficiency of the planetary transmission is:

$$
\eta_{0}=\eta_{14}^{H}=\eta_{12}^{H} \cdot \eta_{23}^{H} \cdot \eta_{34}^{H}=\eta_{g}^{3},
$$

where $\eta_{x y}^{H}$ is the efficiency of the fixed-axis gear mechanism consisting of gears $x$ and $y$ (considering $H \equiv 0$ ), while $\eta_{g}$ is the efficiency of a component gear pair; in this case, the three cylindrical fixed-axis gear pairs (1-2, 2-3, and 3-4) are considered to have identical efficiency values.

With a differential wind system having two counter-rotating inputs and a conventional generator, Figure $2 \mathrm{~b}$, the equation $T_{G S}+T_{H S}=0$ in system (7) has to be replaced by $T_{H S}$ $=0$, as the connection of stator GS to wind rotor $R 1$ is broken and then fixed to the frame $\left(\omega_{G S}=0\right)$.

In the general case 2 in- 2 out, the efficiency of speed increaser can be obtained starting from its definition:

$$
\eta=-\frac{\omega_{G R} T_{G R}+\omega_{G S} T_{G S}}{\omega_{R 1} T_{R 1}+\omega_{R 2} T_{R 2}},
$$

from which - after some algebraic processing of the systems of Equations (1) and (7) the efficiency for wind turbines with two counter-rotating rotors and counter-rotating generator can be expressed by:

$$
\eta=\eta_{0}
$$

as well as for wind turbines with conventional generator:

$$
\eta=\eta_{0} \frac{1-i_{0}\left(1+k_{\omega}\right)}{\eta_{0}-i_{0}\left(1+k_{\omega}\right)}
$$

\subsection{Steady-State Operational Point}

The operational point of a motor-mechanism-effector type machine is the set of values of the external parameters (kinematic and static) of the mechanism at which the machine operates in steady-state mode. The operational point is obtained by solving the system of equations consisting of the kinematic and static transmitting functions of the speed increaser, Equations (1) and (7), and:

- the mechanical characteristics of the two wind rotors $R 1$ and $R 2$, described as linear functions with constant coefficients under stationary conditions (constant wind speed, same values of pitch angles):

$$
\left\{\begin{array}{c}
T_{R 1}=-a_{R 1} \omega_{R 1}+b_{R 1} \\
T_{R 2}=-a_{R 2} \omega_{R 2}+b_{R 2}
\end{array}\right.
$$

- the mechanical characteristic of $D C$ generator, represented by a linear function with constant coefficients, describing generator's torque $T_{G}$ in relation to angular speed $\omega_{G}$. By convention, the torque of the generator is $T_{G}=T_{G R}$ :

$$
-T_{G}=a_{G} \omega_{G}-b_{G} .
$$

Usually, the values of the power parameters on a shaft are first obtained by reducing the mechanical characteristics to that shaft and solving analytically or grapho-analytically the point of intersection between the reduced mechanical characteristics. 
Further on, the operational point $(F)$ at the level of the electric generator is analytically determined, by considering the operating angular speed $\omega_{F}=\omega_{G}$ and the torque $T_{F}=T_{G}$. Thus, for the two analyzed wind systems, the following expressions of parameters $\omega_{F}, T_{F}$ and power $P_{F}$ are obtained:

- for the wind system with counter-rotating generator, Figure 2a:

$$
\left\{\begin{array}{l}
\omega_{F}=\frac{b_{G}-\frac{b_{R 1} \eta_{0}}{i_{0}}}{a_{G}+\frac{a_{R 1} \eta_{0}}{i_{0}^{2}\left(1+k_{\omega}\right)}} ; \\
T_{F}=-a_{G} \omega_{F}+b_{G} ; \quad P_{F}=\omega_{F} T_{F} .
\end{array}\right.
$$

- $\quad$ for the wind system with conventional generator, Figure $2 b$ :

$$
\left\{\begin{array}{l}
\omega_{F}=\frac{b_{G}-\frac{b_{R 1} \eta_{0}}{i_{0}-\eta_{0}}}{a_{R 1} \eta_{0}} \\
T_{F}=-a_{G} \omega_{F}+b_{G} ; \quad P_{F}=\omega_{F} T_{F} .
\end{array}\right.
$$

\subsection{Input Angular Speeds Ratio $k_{\omega}$}

Generally, the input speeds ratio $k_{\omega}$ depends on the mechanical characteristics of the motor and effector sub-systems and on the intrinsic parameters of the speed increaser (i.e., $i_{0}$ and $\left.\eta_{0}\right)$; in practical applications, ratio $k_{\omega}$ can be adjusted to a given value by modifying appropriately at least one mechanical characteristic through different approaches, e.g., by changing the pitch angle of the blades, or controlling the electric generator.

The analytical expressions of ratio $k_{\omega}$ for the two wind systems considered in this comparative analysis can be obtained by processing Equations (1), (3), (4), (6), (7), (12) and (13). Thus, in the case of a system with counter-rotating generator (Figure 2a), it can be concluded from Equation (7) that:

$$
\left\{\begin{array}{l}
T_{1}=T_{H} \frac{\eta_{0}}{i_{0}}=-T_{4} \frac{\eta_{0}}{i_{0}} \Rightarrow T_{H}=-T_{4} \Rightarrow T_{R 2}=-T_{R 1} \\
T_{4}=-T_{1} \frac{i_{0}}{\eta_{0}} \Rightarrow T_{1}=T_{G} \Rightarrow T_{R 2}=-T_{G} \frac{i_{0}}{\eta_{0}}
\end{array}\right.
$$

By replacing the mechanical characteristics of the wind rotors and electric generator from Equations (12) and (13) in Equation (16), and corroborating with Equations (3) and (4), we get:

$$
\left\{\begin{array}{l}
-a_{R 2} \omega_{R 2}+b_{R 2}=a_{R 1} \omega_{R 1}-b_{R 1} \\
-a_{R 2} \omega_{R 2}+b_{R 2}=a_{G} \omega_{g e} \frac{i_{0}}{\eta_{0}}-b_{G} \frac{i_{0}}{\eta_{0}} ; \\
\omega_{R 2}=-k_{\omega} \omega_{R 1} ; \\
\omega_{G}=-\omega_{R 1} i_{0}\left(1+k_{\omega}\right),
\end{array}\right.
$$

which allows one to obtain the expression of $k_{\omega}$ :

$$
k_{\omega}=-\frac{a_{R 1} b_{G} i_{0}+a_{R 1} b_{R 2} \eta_{0}+a_{G} b_{R 1} i_{0}^{2}+a_{G} b_{R 2} i_{0}^{2}}{a_{R 2} b_{R 1} \eta_{0}+a_{G} b_{R 1} i_{0}^{2}+a_{G} b_{R 2} i_{0}^{2}-a_{R 2} b_{G} i_{0}} .
$$

Similarly, the following correlations can be written for the system with conventional generator (Figure 2b):

$$
\left\{\begin{array}{l}
T_{1}=-T_{H} \frac{\eta_{0}}{\eta_{0}-i_{0}}=-T_{4} \frac{\eta_{0}}{i_{0}} \Rightarrow T_{4}=T_{H} \frac{i_{0}}{\eta_{0}-i_{0}} \Rightarrow T_{R 2}=T_{R 1} \frac{i_{0}}{\eta_{0}-i_{0}} ; \\
T_{4}=-T_{1} \frac{i_{0}}{\eta_{0}} \Rightarrow T_{1}=T_{G} \Rightarrow T_{R 2}=-T_{G} \frac{i_{0}}{\eta_{0}},
\end{array}\right.
$$


and by combining them with Equations (3), (6), (7), (12) and (13), we get:

$$
\left\{\begin{array}{l}
-a_{R 2} \omega_{R 2}+b_{R 2}=a_{R 1} \frac{i_{0}}{\eta_{0}-i_{0}} \omega_{R 1}-b_{R 1} \frac{i_{0}}{\eta_{0}-i_{0}} ; \\
-a_{R 2} \omega_{R 2}+b_{R 2}=a_{G} \omega_{G} \frac{i_{0}}{\eta_{0}}-b_{G} \frac{i_{0}}{\eta_{0}} ; \\
\omega_{R 2}=-k_{\omega} \omega_{R 1} ; \\
\omega_{G}=\omega_{R 1}\left[1-i_{0}\left(1+k_{\omega}\right)\right] .
\end{array}\right.
$$

The $k_{\omega}$ expression is the result of solving the system of Equation (20):

$$
k_{\omega}=-\frac{a_{R 1} b_{G} i_{0}+a_{R 1} b_{R 2} \eta_{0}+a_{G} b_{R 2}\left(\eta_{0}-i_{0}\right)-a_{G} b_{R 2} i_{0}\left(\eta_{0}-i_{0}\right)-a_{G} b_{R 1} i_{0}\left(1-i_{0}\right)}{a_{R 2} b_{G}\left(\eta_{0}-i_{0}\right)+a_{R 2} b_{R 1} \eta_{0}+a_{G} b_{R 1} i_{0}^{2}-a_{G} b_{R 2} i_{0}\left(\eta_{0}-i_{0}\right)} .
$$

The influence of ratio $k_{\omega}$ on the behavior of the two wind turbines is herein considered by adjusting only the mechanical characteristic of the secondary wind rotor $R 2$ and keeping unchanged the mechanical characteristics of wind rotor $R 1$ and the electric generator. Under these assumptions, coefficients $a_{R 2}$ and $b_{R 2}$ become variables which are dependent on both ratio $k_{\omega}$ and the constant coefficients of the mechanical characteristic of primary rotor $R 1$.

Thus, the following equation is obtained for the wind system with counter-rotating generator (Figure 2a), by considering the equality $T_{R 2}=-T_{R 1}$ from Equation (16):

$$
-\omega_{R 1}\left(a_{R 1}+a_{R 2} k_{\omega}\right)+b_{R 1}+b_{R 2}=0,
$$

where $\omega_{R 1}$ is the independent parameter; this equality is mathematically satisfied only if the following two conditions are met simultaneously:

$$
\left\{\begin{array}{l}
a_{R 1}+a_{R 2} k_{\omega}=0 \\
b_{R 1}+b_{R 2}=0
\end{array}\right.
$$

which leads to the solution:

$$
\left\{\begin{array}{l}
a_{R 2}=a_{R 1} / k_{\omega} ; \\
b_{R 2}=-b_{R 1}
\end{array}\right.
$$

Similarly, for the wind turbine system with conventional generator (Figure $2 b$ ), the starting point is established from the equality deduced in Equation (19):

$$
T_{R 2}=T_{R 1} \frac{i_{0}}{\eta_{0}-i_{0}}
$$

from which Equation (26) is obtained as function of $\omega_{R 1}$ :

$$
\omega_{R 1}\left[a_{R 1} i_{0}+a_{R 2}\left(\eta_{0}-i_{0}\right) k_{\omega}\right]-b_{R 1} i_{0}+b_{R 2}\left(\eta_{0}-i_{0}\right)=0,
$$

as well as the expressions of coefficients $a_{R 2}$ and $b_{R 2}$ are determined:

$$
\left\{\begin{array}{l}
a_{R 2}=-a_{R 1} i_{0} /\left[\left(\eta_{0}-i_{0}\right) k_{\omega}\right] \\
b_{R 2}=b_{R 1} i_{0} /\left(\eta_{0}-i_{0}\right)
\end{array}\right.
$$

For comparison, the relations for the kinematic and static parameters of the two wind systems are tabulated below (see Table 1); the relations are established as functions of the parameters of primary wind rotor $R 1$ in the analytical modeling presented above. 
Table 1. The analytical expressions of the kinematic and static parameters of the wind systems.

\begin{tabular}{|c|c|c|c|}
\hline Parameter & Symbol & $\begin{array}{l}\text { Wind System } \\
2 \text { in-2 out, } \\
\text { Figure 2a }\end{array}$ & $\begin{array}{l}\text { Wind System } \\
2 \text { in-1 out, } \\
\text { Figure } 2 \text { b }\end{array}$ \\
\hline Amplification kinematic ratio & $i_{a}=\frac{\omega_{G}}{\omega_{R 1}}$ & $-i_{0}\left(1+k_{\omega}\right)$ & $1-i_{0}\left(1+k_{\omega}\right)$ \\
\hline Efficiency & $\eta$ & $\eta_{0}$ & $\eta_{0} \frac{1-i_{0}\left(1+k_{\omega}\right)}{\eta_{0}-i_{0}\left(1+k_{\omega}\right)}$ \\
\hline $\begin{array}{l}\text { Angular speed of the } \\
\text { generator }\end{array}$ & $\omega_{G}=\omega_{G R}-\omega_{G S}$ & $-\omega_{R 1} i_{0}\left(1+k_{\omega}\right)$ & $\omega_{R 1}\left[1-i_{0}\left(1+k_{\omega}\right)\right]$ \\
\hline Generator torque & $T_{G}=T_{G R}$ & $-T_{R 1} \frac{\eta_{0}}{\eta_{0}-i_{0}}$ & $-T_{R 1} \frac{\eta_{0}}{\eta_{0}-i_{0}}$ \\
\hline Generator power & $P_{G}=T_{G} \omega_{G}$ & $T_{R 1} \omega_{R 1} \eta_{0} \frac{i_{0}\left(1+k_{\omega}\right)}{\eta_{0}-i_{0}}$ & $-T_{R 1} \omega_{R 1} \eta_{0} \frac{1-i_{0}\left(1+k_{\omega}\right)}{\eta_{0}-i_{0}}$ \\
\hline $\begin{array}{l}\text { Angular speed of the } \\
\text { generator rotor }\end{array}$ & $\omega_{G R}$ & $\omega_{R 1}\left[1-i_{0}\left(1+k_{\omega}\right)\right]$ & $\omega_{R 1}\left[1-i_{0}\left(1+k_{\omega}\right)\right]$ \\
\hline Generator rotor torque & $T_{G R}$ & $T_{R 1} \frac{\eta_{0}}{i_{0}}$ & $T_{R 1} \frac{\eta_{0}}{i_{0}}$ \\
\hline Generator rotor power & $P_{G R}$ & $T_{R 1} \omega_{R 1} \frac{\eta_{0}\left[1-i_{0}\left(k_{\omega}+1\right)\right]}{i_{0}}$ & $T_{R 1} \omega_{R 1} \frac{\eta_{0}\left[1-i_{0}\left(k_{\omega}+1\right)\right]}{i_{0}}$ \\
\hline $\begin{array}{l}\text { Angular speed of the } \\
\text { generator stator }\end{array}$ & $\omega_{G S}$ & $\omega_{R 1}$ & 0 \\
\hline Generator stator torque & $T_{G S}$ & $-T_{R 1} \frac{\eta_{0}}{i_{0}}$ & $-T_{R 1} \frac{\eta_{0}}{i_{0}}$ \\
\hline Generator stator power & $P_{G S}$ & $-T_{R 1} \omega_{R 1} \frac{\eta_{0}}{i_{0}}$ & 0 \\
\hline Angular speed of the carrier $H$ & $\omega_{H}$ & $\omega_{R 1}$ & $\omega_{R 1}$ \\
\hline$H$ carrier torque & $T_{H}$ & $T_{R 1}$ & $T_{R 1}$ \\
\hline$H$ carrier power & $P_{H}$ & $T_{R 1} \omega_{R 1}$ & $T_{R 1} \omega_{R 1}$ \\
\hline Angular speed of the shaft $H R$ & $\omega_{H R}$ & $\omega_{R 1}$ & $\omega_{R 1}$ \\
\hline$H R$ shaft torque & $T_{H R}$ & $T_{R 1} \frac{i_{0}-\eta_{0}}{i_{0}}$ & $T_{R 1}$ \\
\hline$H R$ shaft power & $P_{H R}$ & $T_{R 1} \omega_{R 1} \frac{i_{0}-\eta_{0}}{i_{0}}$ & $T_{R 1} \omega_{R 1}$ \\
\hline Angular speed of shaft $H S$ & $\omega_{H S}$ & $\omega_{R 1}$ & 0 \\
\hline HS shaft torque & $T_{H S}$ & $T_{R 1} \frac{\eta_{0}}{i_{0}}$ & $T_{R 1} \frac{\eta_{0}}{i_{0}}$ \\
\hline HS shaft power & $P_{H S}$ & $T_{R 1} \omega_{R 1} \frac{\eta_{0}}{i_{0}}$ & 0 \\
\hline Angular speed of gear 4 & $\omega_{4}$ & $-k_{\omega} \omega_{R 1}$ & $-k_{\omega} \omega_{R 1}$ \\
\hline Torque on gear 4 & $T_{4}$ & $-T_{R 1}$ & $-T_{R 1} \frac{i_{0}}{i_{0}-\eta_{0}}$ \\
\hline Power of gear 4 & $P_{4}$ & $k_{\omega} T_{R 1} \omega_{R 1}$ & $\omega_{R 1} T_{R 1} \frac{k_{\omega} i_{0}}{i_{0}-\eta_{0}}$ \\
\hline
\end{tabular}

The analytical relations for the wind system with conventional electric generator (2 in-1 out, last column of Table 1) were obtained by the appropriate customization of the general model described for the case of the system with counter-rotating generator, i.e., breaking the connection between $H$ and $S G$ (i.e., $T_{H S}=0$ ) and fixing the stator $S G$ to the frame (i.e., $\omega_{S G}=0$ ). The analysis of the relations from Table 1 can highlight the following properties of wind systems of 2 in- 2 out type compared to 2 in- 1 out type systems:

- achieve a kinematic amplification ratio, in absolute value, higher than 1 (as both the ratios $i_{0}$ and $k_{\omega}$ have positive values);

- $\quad$ have a higher efficiency, which does not depend on the kinematic configuration of the speed increaser and which is equal to the internal efficiency $\eta_{0}$;

- $\quad$ ensure the operation with higher angular speeds $\omega_{G}$ and powers $P_{G}$ of the electric generator, for the same power of the primary wind rotor $P_{R 1}=T_{R 1} \omega_{R 1}$;

- $\quad$ the wind rotor $R 2$ operates at lower torques and powers. 


\section{Numerical Simulations and Discussions}

The comparative analysis of the performance of the two wind systems presented above, which integrate the same planetary speed increaser (i.e., the same values of the intrinsic parameters $i_{0}$ and $\eta_{0}$ ), is performed under equivalence conditions, by considering the following three numerical simulation scenarios:

Scenario $A$ : the two wind turbines use the same wind rotors $R 1$ and $R 2$, as well as the same electric generator-used as a counter-rotating generator with the 2 in- 2 out wind system (Figure 2a) and as a conventional generator with the 2 in- 1 out wind system (Figure $2 \mathrm{~b}$ ). In this scenario, rotors $R 1$ and $R 2$ are identical and, therefore, have identical mechanical characteristics with the same constant coefficients.

Scenario B: very similar to Scenario $A$, except that rotors $R 1$ and $R 2$ are different and, as a result, they have mechanical characteristics with different constant coefficients.

Scenario C: derived from Scenario B, with the difference that secondary wind rotors $R 2$ are adjusted differently in the two wind turbines (coefficients of mechanical characteristics for rotors $R 2$ are different), with a view to providing the same value of ratio $k_{\omega}$.

These scenarios aim at determining the operational points of the two wind turbines, i.e., the values of angular speed and torque for the external connections of the mechanism, which allow the calculation of the efficiency and output power. Therefore, Equations (14) and (15) are used to obtain the operational point of the rotor GR shaft, which allows the identification of the operational point of the primary wind rotor $R 1$ and then all the other parameters, based on the relations in Table 1.

The intrinsic parameters of the planetary speed increaser remain constant in all scenarios, the following values being considered in the simulations: $i_{0}=10$ and $\eta_{0}=\eta_{g}^{3}=$ $0.95^{3}=0.857$.

\subsection{Scenario A}

In this scenario, the two wind turbines are characterized by the following features, see Rel. (7):

- $\quad$ wind rotors $R 1$ and $R 2$ are identical, since they have the same mechanical characteristics: $T_{R 1}=-a_{R 1} \omega_{R 1}+b_{R 1}=-18.763 \omega_{R 1}-204.81$ and $T_{R 2}=-a_{R 2} \omega_{R 2}+b_{R 2}=$ $-18.763 \omega_{R 2}+204.81$

- $\quad$ electric generators have the same mechanical characteristic $-T_{G}=-a_{G} \omega_{R 1}-b_{G}=$ $-; 0.4 \omega_{G}-35$.

The results of the numerical simulations for the operational points of the two wind turbines are tabulated below (see Table 2).

Table 2. The values of the parameters related to the steady-state operational point for Scenario A.

\begin{tabular}{ccc}
\hline Parameter & $\begin{array}{c}\text { Wind System 2 in-2 out, } \\
\text { Figure 2a }\end{array}$ & $\begin{array}{c}\text { Wind System 2 in-1 out, } \\
\text { Figure } 2 \mathbf{b}\end{array}$ \\
\hline$\omega_{R 1}\left[\mathrm{~s}^{-1}\right]$ & -5.470 & -5.989 \\
$T_{R 1}[\mathrm{kNm}]$ & -102.176 & -92.438 \\
$P_{R 1}[\mathrm{~kW}]$ & 558.905 & 553.613 \\
$\omega_{R 2}\left[\mathrm{~s}^{-1}\right]$ & 5.470 & 5.527 \\
$T_{R 2}[\mathrm{kNm}]$ & 102.176 & 101.106 \\
$P_{R 2}[\mathrm{~kW}]$ & 558.905 & 558.818 \\
$\omega_{G}\left[\mathrm{~s}^{-1}\right]$ & 109.401 & 109.171 \\
$T_{G}[\mathrm{kNm}]$ & -8.760 & -8.669 \\
$P_{G}[\mathrm{~kW}]$ & -958.382 & -946.366 \\
$\eta$ & 0.8573 & 0.8507 \\
$k_{\omega}$ & 1.000 & 0.923 \\
$i_{a}=\omega_{G} / \omega_{R 1}$ & -20.000 & -17.209 \\
\hline$a_{R 1}=a_{R 2}=18.763[\mathrm{kNms}] ; b_{R 1}=b_{R 2}=-204.81[\mathrm{kNm}] ; a_{G}=0.4[\mathrm{kNms}] ; b_{G}=35[\mathrm{kNm}] ; i_{0}=10 ; \eta_{0}=0.857$.
\end{tabular}


From these numerical results, the following conclusions can be drawn: compared to the 2 in- 1 out wind system, the wind turbine with counter-rotating generator ( 2 in- 2 out) operates at a higher efficiency $(85.73 \%$ vs. $85.07 \%)$, ensures a higher amplification ratio in absolute value (20.00 vs. 17.21) and has a higher power by approx. 1.3\% (958.38 vs. 946.37). Both wind rotors have similar lower angular speeds and higher torques, which leads to close input powers. As a result, when using identical wind rotors $R 1$ and $R 2$ in both systems and constant intrinsic parameters of the speed increaser and the considered mechanical characteristics, the wind turbine with a counter-rotating generator ensures slightly higher performance than the wind turbine with a conventional generator. Although preferred in terms of performance, the 2 in- 2 out wind turbine can be surpassed by the 2 in- 1 out turbine due to an increased complexity of the counter-rotating electric generator-if an economically-grounded multicriteria analysis might be performed.

\subsection{Scenario $B$}

The facts and figures in Scenario A change significantly by using secondary wind rotors which are different from the primary ones. Therefore, the Scenario B aims at identifying the operational point of the two wind turbines by considering, for both types of wind system:

- $\quad$ the same wind rotor $R 1$, with the mechanical characteristic $T_{R 1}=-a_{R 1} \omega_{R 1}+b_{R 1}=$ $-18.763 \omega_{R 1}-204.81$

- $\quad$ the same wind rotor $R 2$, with the mechanical characteristic $T_{R 2}=-a_{R 2} \omega_{R 2}+b_{R 2}=$ $-18.763 \omega_{R 2}+204.81$; established from the condition that the two wind turbines generate equal power;

- $\quad$ the same electric generator, with the mechanical characteristic $T_{G}=-a_{G} \omega_{R 1}-b_{G}=$ $-0.4 \omega_{G}-35$.

Under these conditions, the two wind turbines are stabilized in steady-state at the operational point values listed in Table 3 below.

Table 3. The values of the parameters related to the steady-state operational point for Scenario B.

\begin{tabular}{ccc}
\hline Parameter & $\begin{array}{c}\text { Wind System 2 in-2 out, } \\
\text { Figure 2a }\end{array}$ & $\begin{array}{c}\text { Wind System 2 in-1 out, } \\
\text { Figure } 2 \mathbf{b}\end{array}$ \\
\hline$\omega_{R 1}\left[\mathrm{~s}^{-1}\right]$ & -4.754 & -5.283 \\
$T_{R 1}[\mathrm{kNm}]$ & -115.604 & -105.693 \\
$P_{R 1}[\mathrm{~kW}]$ & 549.622 & 558.332 \\
$\omega_{R 2}\left[\mathrm{~s}^{-1}\right]$ & 6.474 & 6.474 \\
$T_{R 2}[\mathrm{kNm}]$ & 115.604 & 115.604 \\
$P_{R 2}[\mathrm{~kW}]$ & 748.372 & 748.372 \\
$\omega_{G}\left[\mathrm{~s}^{-1}\right]$ & 112.279 & 112.279 \\
$T_{G}[\mathrm{kNm}]$ & -9.912 & -9.912 \\
$P_{G}[\mathrm{~kW}]$ & -1112.868 & -1112.868 \\
$\eta$ & 0.8574 & 0.8516 \\
$k_{\omega}$ & 1.362 & 1.225 \\
$i_{a}=\omega_{G} / \omega_{R 1}$ & -23.616 & -21.255 \\
\hline$\left.a_{R 1}=18.763[\mathrm{kNms}] ;\right] ; b_{R 1}-204.81[\mathrm{kNm}] ; a_{R 2}=13.780[\mathrm{kNms}] ; b_{R 2}=204.81[\mathrm{kNm}] ; a_{G}=0.4[\mathrm{kNms}] ; b_{G}=35$
\end{tabular}

$[\mathrm{kNm}] ; i_{0}=10 ; \eta_{0}=0.857$.

Under the condition of equal output power, used for driving the electric generator, it is found that wind rotor $R 2$ extracts the same power from the wind in both systems, while primary wind rotor $R 1$ operates at higher parameters with 2 in- 1 out wind turbine. Instead, the wind system with a counter-rotating generator has slightly better efficiency $(85.74 \%$ vs. $85.16 \%$ ), which provides the energy compensation required to obtain a power output equal to that of the system with a conventional generator. Choosing the secondary wind rotor (by setting the coefficient $a_{R 2}$ ) is a challenging task for designers, which can lead to changing the option for one or the other type of wind turbine. Parameters marked by asterisk $\left(^{*}\right)$ in the following diagrams, Figure 5, refer to the wind turbine with a conventional generator. 


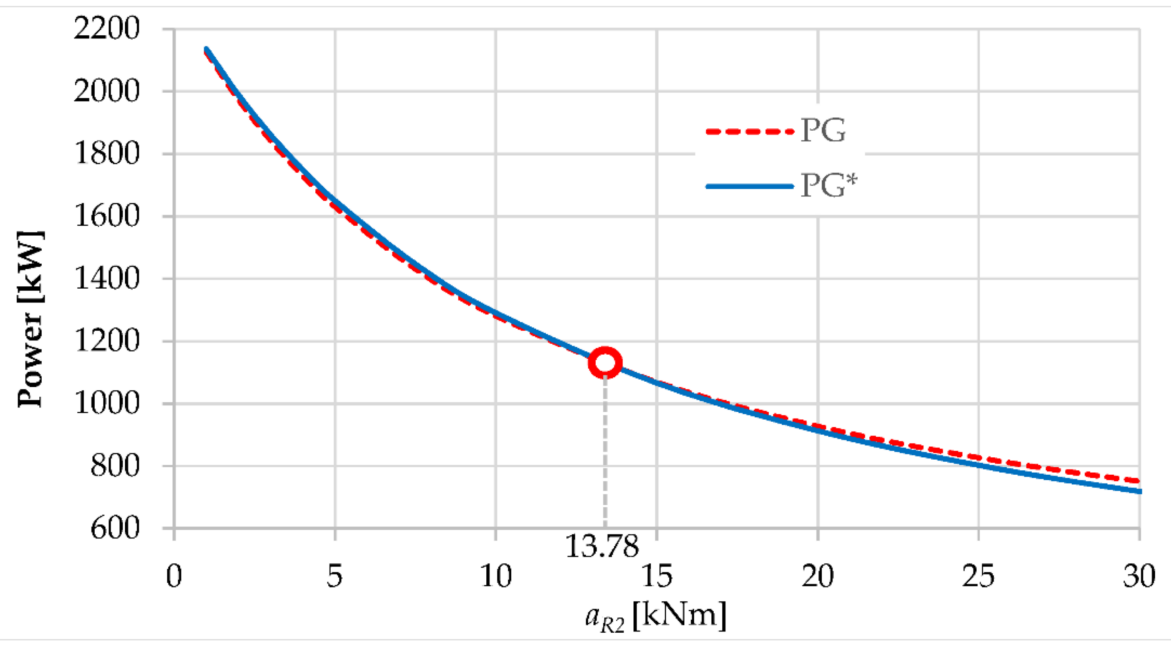

(a)

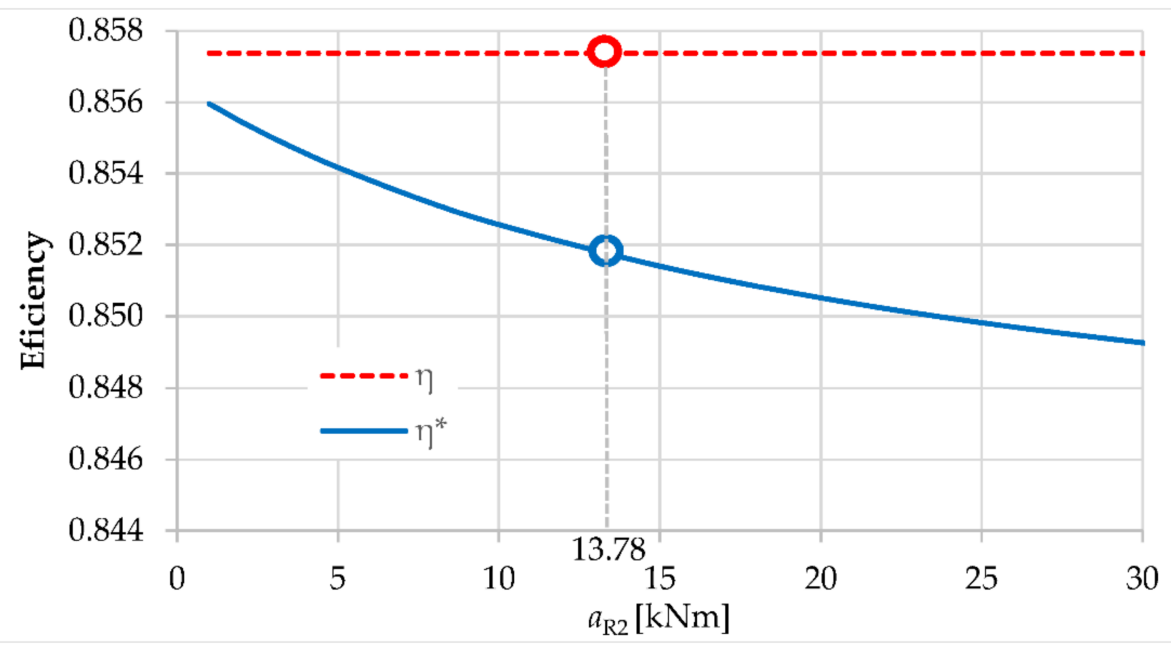

(b)

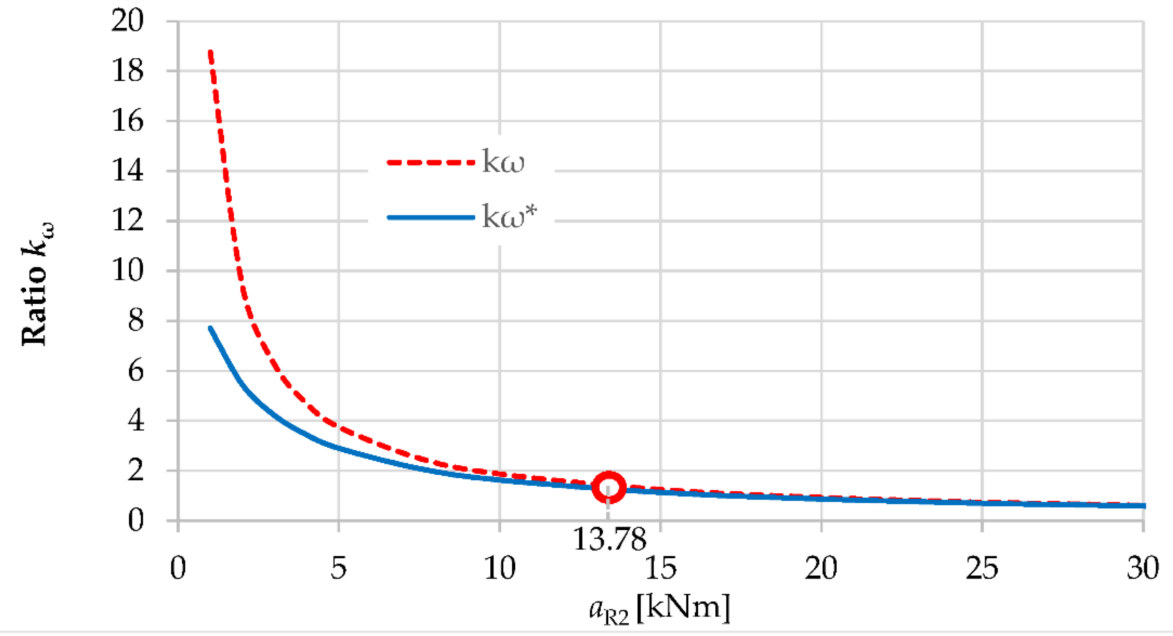

(c)

Figure 5. Variation with respect to $a_{R 2}$ coefficient of: (a) output power, (b) efficiency and (c) ratio $k_{\boldsymbol{\omega}}$, in both wind systems.

According to Figure 5a, the wind turbine with a conventional generator ensures an output power ( $P G^{*}$ curve) higher than that of the 2 in- 2 out turbine, for values of coefficient $a_{R 2}<13.78$, and generates power values significantly close to those of the turbine with a 
counter-rotating generator (PG curve), for values of coefficient $a_{R 2}>13.78$. The efficiency of the conventional turbine decreases with the increase of values for $a_{R 2}$ (see Figure $5 \mathrm{~b}$ ). In all instances, the wind turbine with a counter-rotating generator is stabilized at higher values of ratio $k_{\omega}$, i.e., a greater difference between input speeds, but with less significant differences for $a_{R 2}>13.78$ (see Figure $5 \mathrm{c}$ ).

Thus, it should be emphasized that the performance of the two wind systems is significantly influenced by the external mechanical characteristics, modified in this study by changing the coefficient values $a_{R 1}=a_{R 2}$.

\subsection{Scenario $C$}

The Scenario $C$ is an extension of the Scenario B, by ensuring the additional condition of obtaining the same ratio $k_{\omega}$ for both wind turbines. Under the conditions of maintaining the same primary wind rotor $R 1$ and the same electric generator as in Scenarios $A$ and $B$, this goal can only be achieved if the secondary wind rotors $R 2$ are different, i.e., $a_{R 2} \neq a_{R 2}^{*}$ and $b_{R 2} \neq b_{R 2}^{*}$. As a case study, the target value of ratio $k_{\omega}=2.5$ is further considered and, therefore, the coefficients of the mechanical characteristics of rotors $R 2$ can be calculated, by means of Equations (24) and (27). The values of the steady-state operational points for the two wind turbines are displayed in Table 4 below. As in Scenario B, the parameters marked by * refer to the wind system with a conventional generator.

Table 4. The values of the parameters related to the steady-state operational point for Scenario C.

\begin{tabular}{ccc}
\hline \multirow{2}{*}{ Parameter } & $\begin{array}{c}\text { Wind System } \mathbf{2} \text { in-2 out, } \\
\text { Figure } 2 \mathbf{a}\end{array}$ & $\begin{array}{c}\text { Wind System } \mathbf{2} \text { in-1 out, } \\
\text { Figure } 2 \mathbf{b}\end{array}$ \\
\hline$\omega_{R 1}\left[\mathrm{~s}^{-1}\right]$ & -3.367 & -3.529 \\
$T_{R 1}[\mathrm{kNm}]$ & -141.630 & -138.592 \\
$P_{R 1}[\mathrm{~kW}]$ & 476.908 & 489.117 \\
$\omega_{R 2}\left[\mathrm{~s}^{-1}\right]$ & 8.418 & 8.823 \\
$T_{R 2}[\mathrm{kNm}]$ & 141.630 & 151.589 \\
$P_{R 2}[\mathrm{~kW}]$ & 1192.301 & 1337.455 \\
$\omega_{G}\left[\mathrm{~s}^{-1}\right]$ & 117.857 & 119.992 \\
$T_{G}[\mathrm{kNm}]$ & -12.143 & -12.997 \\
$P_{G}[\mathrm{~kW}]$ & -1431.138 & -1559.516 \\
$\eta$ & 0.8574 & 0.8538 \\
$i_{a}=\omega_{G} / \omega_{R 1}$ & -35.000 & -34.000 \\
\hline$\left.a_{R 1}=18.763[\mathrm{kNms}] ;\right] ; b_{R 1}-204.81[\mathrm{kNm}] ; a_{R 2}=7.505[\mathrm{kNms}] ; b_{R 2}=204.81[\mathrm{kNm}] ; k_{\omega}=2.5 ; a^{*} R 2=8.209[\mathrm{kNms}]$ \\
$b_{R 2}^{*}=224.016[\mathrm{kNm}] ; a_{G}=0.4[\mathrm{kNms}] ; b_{G}-35[\mathrm{kNm}] ; i_{0}=10 ; \eta_{0}=0.857$.
\end{tabular}

According to the results in Tables 2-4 and Figure 6a, it can be concluded that the efficiency of the speed increaser is higher with systems having a counter-rotating generator, as a result of in-parallel transmission of the output mechanical power, compared to wind systems with a conventional generator. The efficiency dependence on ratio $k_{\omega}$-described by Equations (10) and (11) and illustrated in Figure 6a-highlights the fact that efficiency of a 2 in- 2 out wind system is constant and always higher than that achieved by a 2 in- 1 out system, whose values tend to infinity toward this constant value. Thus, the efficiency of the two wind systems can have close values only for very high values of $k_{\omega}$, which is not justified in the operation of a wind system with counter-rotating rotors. 


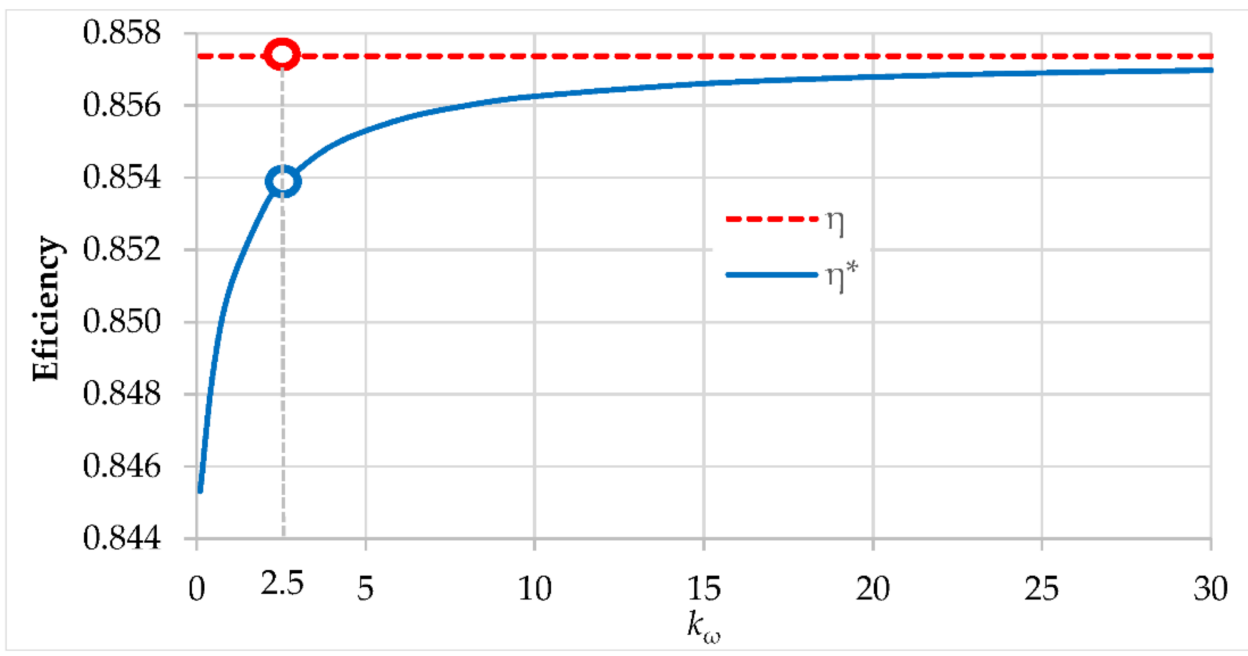

(a)

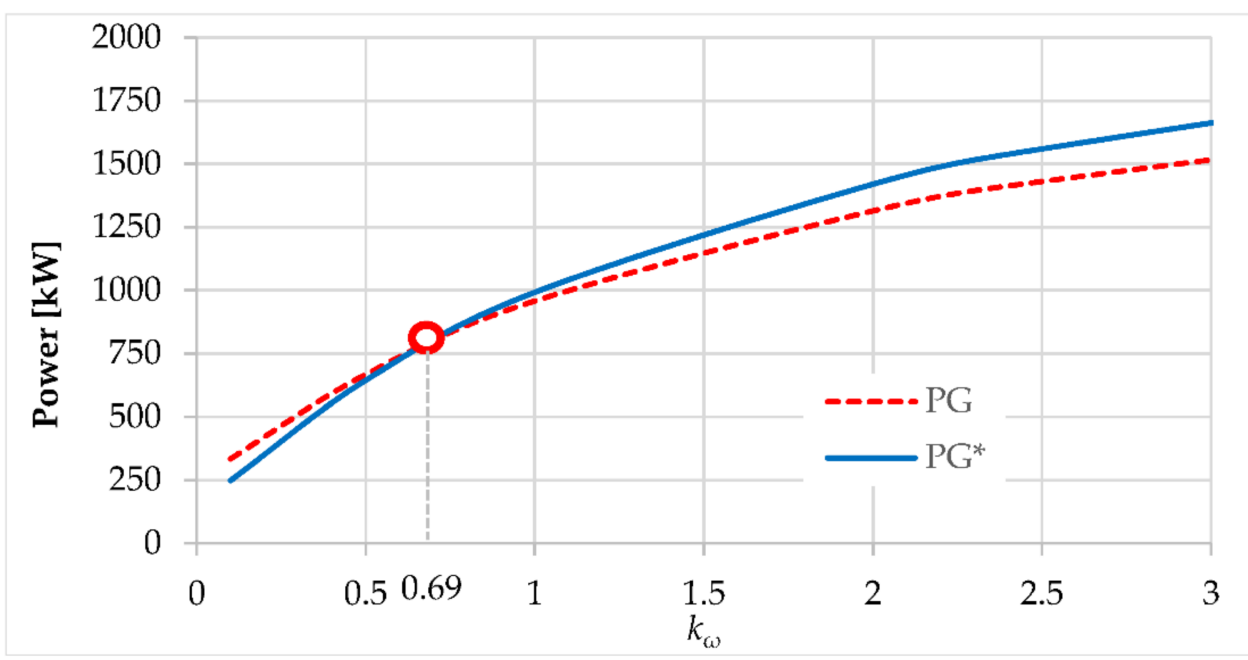

(b)

Figure 6. Variation with respect to ratio $k_{\omega}$ of: (a) efficiency and (b) output power, in both wind systems.

As in Scenario B, the wind turbine with a counter-rotating generator has higher energy performance for low values of ratio $k_{\omega}$ and output power, implicitly (Figure 6b). Instead, the wind turbine with a conventional generator proves to be more efficient for higher values of ratio $k_{\omega}$ and output power.

To conclude the discussions for the three numerical simulation scenarios, the power flows for both wind systems with counter-rotating electric generator (Figure 7a) vs. conventional generator (Figure 7b) are comparatively represented in Figure 7. It is noticeable for both systems the increase of the output power from Scenario A to Scenario C, as well as the effectiveness of the 2 in- 2 out system at lower powers and, respectively, of the 2 in- 1 out system at higher powers. 


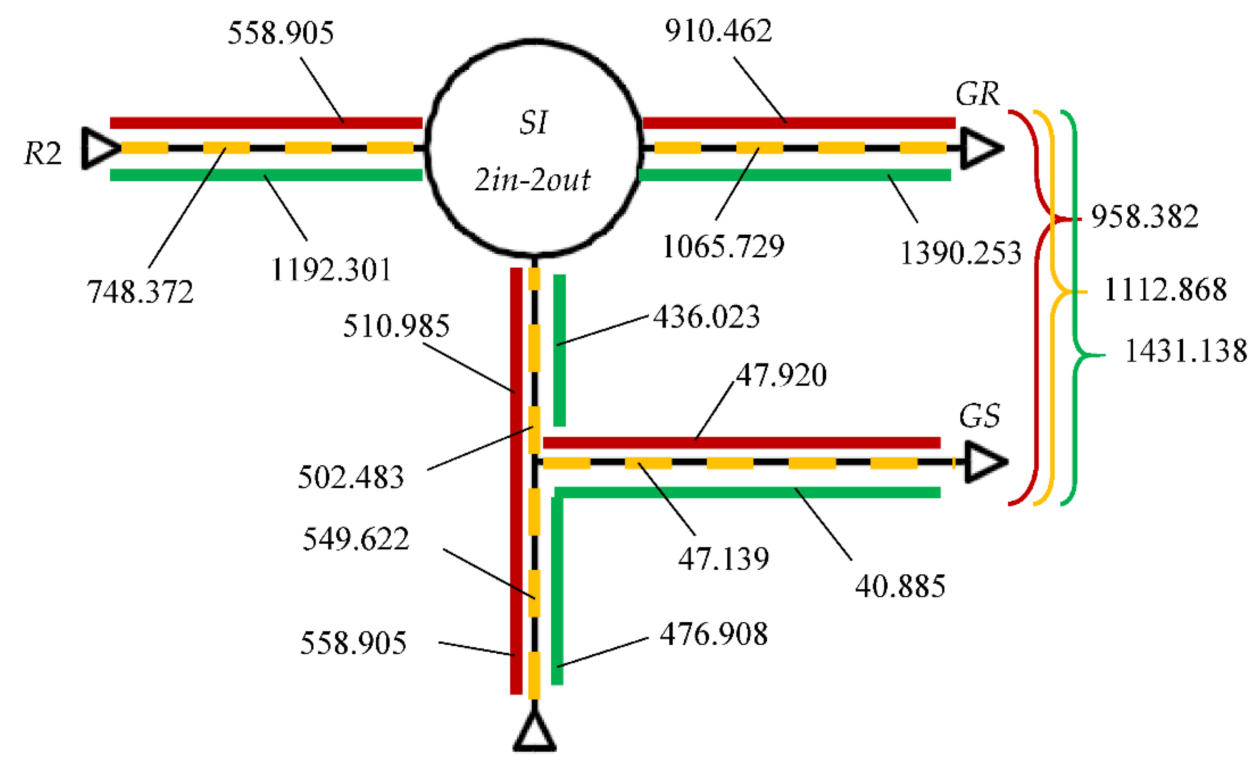

$R 1$

(a)

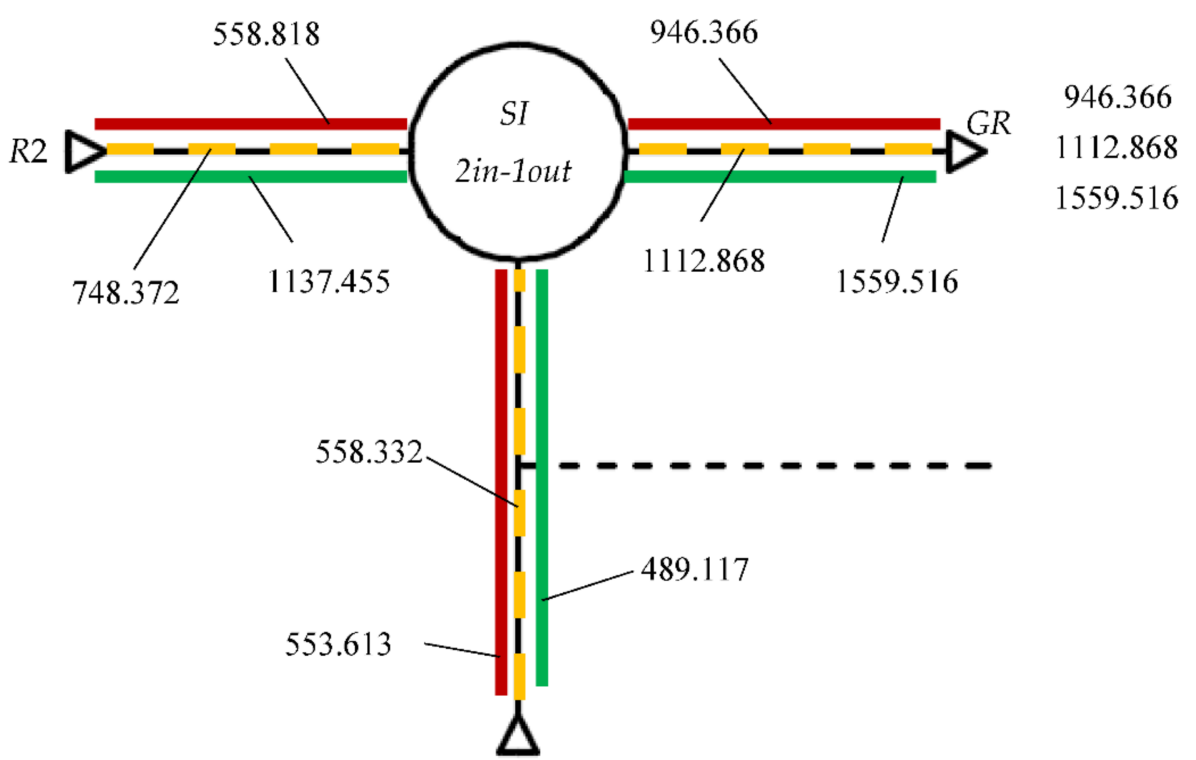

R1

(b)

Figure 7. Power flow in the Scenarios $A$ (continuous red line), $B$ (yellow dashed line) and $C$ (continuous green line) through: (a) 2 in- 2 out wind system; (b) 2 in- 1 out wind system.

\section{Conclusions}

The paper presented a comparative study of the energy performance of wind turbines with two counter-rotating rotors ( $R 1$ and $R 2)$ and differential speed increaser, in the functional configurations with counter-rotating vs. conventional generator. To this end, the analytical modeling of the operational point of the two types of wind system has been presented and numerically analyzed in three scenarios, with distinct situations regarding the way the secondary wind rotor $R 2$ characteristic is chosen: $R 2$ identical to the primary 
wind rotor $R 1$ (Scenario $A$ ); $R 2$ different from $R 1$, and $R 2$ identical in both applications (Scenario B); and $R 2$ different from $R 1$, and $R 2$ different in the two applications (Scenario $C$ ). According to the analyzed scenarios, the comparative study of the numerical results allows drawing the following final conclusions:

- The differential wind system with a counter-rotating electric generator, which is characterized by in-parallel transmission of power at both input and output, always ensures better efficiency of mechanical power transmission from inputs to outputs, compared to the wind system with a conventional generator. In the case of counterrotating outputs, the efficiency of the wind system is equal to the internal efficiency $\eta_{0}$ of the planetary transmission; instead, the efficiency of the wind turbine with a conventional generator is significantly influenced by system parameters (i.e., ratio $k_{\omega}$, coefficients of mechanical characteristics, kinematic ratio $i_{0}$ ), the value $\eta_{0}$ being the upper limit of efficiency variation for this type of wind turbine.

- The energy response of the two types of wind system depends significantly on the characteristics of the selected wind rotors and electric generator. Thus, the advantage of better mechanical efficiency of wind turbines with a counter-rotating generator is accompanied by higher energy performance only in certain system configurationsgenerally, in the range of lower power. Considering the higher complexity of counterrotating electric generators, due to their mobile stator, the designers' decision to choose a type of counter-rotating wind turbine seems to be a compromise between technical, energy and economic performance.

The proposed models are useful in the synthesis of differential speed increasers with counter-rotating inputs and outputs, which ensure higher output speed by speed-adding, in conditions of higher efficiency. Considering these facts, the findings emerged from this contrastive approach might prove particularly useful to wind system designers in selecting the most adequate technical solution, depending on the amount of power needed and the wind potential in the area of implementation.

In the future, the authors intend to generalize the modeling of the behavior of counterrotating wind turbines with counter-rotating electric generator vs. conventional generator in both cases of operation, as a 2-DOF (speed-adding) and a 1-DOF (torque-adding) system, followed by experimental validation of analytical results by developing and using an versatile rig to test these types of counter-rotating wind turbines.

Author Contributions: Conceptualization, R.S. and M.N.; Data curation, R.S., M.N. and C.J.; Formal analysis, R.S, M.N. and C.J.; Investigation, R.S., M.N. and C.J.; Methodology, R.S., M.N., C.J. and O.M.; Software, R.S. and M.N.; Supervision, M.N., C.J. and O.M.; Validation, M.N. and C.J.; Visualization, R.S., M.N., C.J. and O.M.; Writing-original draft, R.S. and M.N.; Writing—review \& editing, C.J. and O.M. All authors have read and agreed to the published version of the manuscript.

Funding: This research received no external funding.

Acknowledgments: The comments, suggestions and recommendations for future research by the anonymous reviewers are gratefully acknowledged.

Conflicts of Interest: The authors declare no conflict of interest. 


\section{Nomenclature}

$\begin{array}{llll}S I & \text { Speed increaser } & \text { DOF } & \text { Degree of freedom } \\ R 1 & \text { Primary wind rotor } & M & \text { Mechanism mobility } \\ R 2 & \text { Secondary wind rotor } & L & \text { Total number of inputs and outputs } \\ P & \text { Power } & G & \text { Electric generator } \\ \omega & \text { Angular speed } & G R & \text { Electric generator rotor } \\ T & \text { Torque } & G S & \text { Electric generator stator } \\ k_{\omega} & \text { Ratio of the input angular speeds } & i & \text { Kinematic ratio } \\ z & \text { Number of gear teeth } & i_{0} & \text { Internal kinematic ratio } \\ H & \text { Satellite carrier } & i_{a} & \text { Amplification kinematic ratio } \\ F & \text { Operational point } & \eta & \text { Efficiency of the speed increaser } \\ a & \text { Angular speed coefficient } & \eta_{0} & \text { Internal efficiency } \\ b & \text { Torque coefficient } & \eta_{g} & \text { Efficiency of a gear pair }\end{array}$

\section{References}

1. Wacinski, A.; Sàrl, E. Drive Device for a Windmill Provided with Two Counter-Rotative Propellers. U.S. Patent 7,384,239, 6 September 2008.

2. Brander, M. Bi-Directional Wind Turbine. U.S. Patent 0,197,639 A1, 21 August 2008.

3. Jaliu, C.; Climescu, O.; Saulescu, R. Speci fic features of a counter-rotating transmission for renewable energy systems. Environ. Eng. Manag. J. 2011, 10, 1105-1113. [CrossRef]

4. Oprina, G.; Chihaia, R.A.; El-Leathey, L.A.; Nicolaie, S.; Babutanu, C.A.; Voina, A. A review on counter-rotating wind tur-bines development. J. Sustain. Energy 2016, 7, 91-98.

5. Shin, C. Multi-Unit Rotor Blade System Integrated Wind Turbine. U.S. Patent 5,876,181, 2 March 1999.

6. Muhtadi, R.Z.; Bramantya, M.A. Experimental study of local pitch variations on electric power generated by counter rotating wind turbine with single generator without gearbox. IOP Conf. Ser. Mater. Sci. Eng. 2018, 434, 012176. [CrossRef]

7. Li, Z.; Wang, Y.; Xiao, H. Experimental study on structures of counter-rotating wind turbines. In Proceedings of the 2013 International Conference on Materials for Renewable Energy and Environment, Chengdu, China, 19-21 August 2013; Volume 1, pp. 368-372. [CrossRef]

8. Pamuji, D.; Bramantya, M. Numerical Study on the Performance Of 2-Bladed and 3-Bladed Counter Rotating Wind Turbines. J. Jpn. Soc. Appl. Electromagn. Mech. 2019, 27, 169-174. [CrossRef]

9. Didane, D.H.; Rosly, N.; Zulkafli, M.F.; Shamsudin, S.S. Performance evaluation of a novel vertical axis wind turbine with coaxial contra-rotating concept. Renew. Energy 2018, 115, 353-361. [CrossRef]

10. West, R. Wind Turbine System. U.S. Patent 10,316,820 B2, 11 June 2019.

11. Vasel-Be-Hagh, A.; Archer, C.L. Wind farms with counter-rotating wind turbines. Sustain. Energy Technol. Assess. 2017, 24, 19-30. [CrossRef]

12. Jaliu, C.; Diaconescu, D.V.; Neagoe, M.; Saulescu, R. Dynamic features of speed increasers from mechatronic wind and hydro systems. Part II. Dynamic aspects. In Proceedings of the Second European Conference on Mechanism Science EUCOMES 08, Casino, Italy, 17-20 September 2008; Springer: Dordrecht, The Netherlands, 2008; pp. 365-373, ISBN 987-1-4020-8914-5.

13. Bevington, C.M.; Bywaters, G.L.; Coleman, C.C.; Costin, D.P.; Danforth, W.L.; Lynch, J.A.; Rolland, R.H. Wind Turbine Having a Direct-Drive Drivetrain. U.S. Patent 7,431,567 B1, 7 October 2008.

14. Marjanovic, N.; Isailovic, B.; Marjanovic, V.; Milojevic, Z.; Blagojevic, M.; Bojic, M. A practical approach to the optimization of gear trains with spur gears. Mech. Mach. Theory 2012, 53, 1-16. [CrossRef]

15. Pastor, D.G.S.B.; Nalianda, D.; Sethi, V.; Midgley, R.; Rolt, A.; Novelo, D.A.B. Preliminary Design Framework for the Power Gearbox in a Contra-Rotating Open Rotor. J. Eng. Gas Turbines Power 2021, 143, 041022. [CrossRef]

16. Jelaska, D.; Podrug, S.; Perkušić, M. A novel hybrid transmission for variable speed wind turbines. Reneww. Energy 2015, 83, 78-84. [CrossRef]

17. Saulescu, R.; Neagoe, M.; Munteanu, O.; Cretescu, N. Performance analysis of a novel planetary speed increaser used in single-rotor wind turbines with counter-rotating electric generator. IOP Conf. Ser. Mater. Sci. Eng. 2016, 147, 012090. [CrossRef]

18. Neagoe, M.; Saulescu, R.; Jaliu, C.; Cretescu, N. Novel Speed increaser used in counter-rotating wind turbines. In New Advances in Mechanisms, Mechanical Transmissions and Robotics, Mechanisms and Machine Science 46; Springer: Berlin, Germany, 2017; pp. 143-151. [CrossRef]

19. Jaliu, C.; Diaconescu, D.V.; Neagoe, M.; Saulescu, R. Dynamic features of speed increasers from mechatronic wind and hydro systems. Part I. Structure Kinematics. In Proceedings of the Second European Conference on Mechanism Science EUCOMES 08, Casino, Italy, 17-20 September 2008; Springer: Dordrecht, The Netherlands, 2008; pp. 355-363, ISBN 987-1-4020-8914-5.

20. Erturk, E.; Sivrioglu, S.; Bolat, F.C. Analysis Model of a Small Scale Counter-Rotating Dual Rotor Wind Turbine with Double Rotational Generator Armature. Int. J. Renew. Energy Res. 2018, 8, 1849-1858.

21. Bharani, R.; Sivaprakasam, A. A Review Analysis on Performance and Classification of Wind Turbine Gearbox Technologies. IETE J. Res. 2020, 1-15. [CrossRef] 
22. Fan, Z.; Zhu, C.; Li, X.; Liang, C. The transmission characteristic for the improved wind turbine gearbox. Energy Sci. Eng. 2019, 7, 1368-1378. [CrossRef]

23. Qiu, J.; Liu, B.; Dong, H.; Wang, D. Type Synthesis of Gear-box in Wind Turbine. Procedia Comput. Sci. 2017, 109, 809-816. [CrossRef]

24. Climescu, O.; Jaliu, C.; Saulescu, R. Comparative Analysis of Horizontal Small Scale Wind Turbines for a Specific Applica-tion. In Proceedings of the 14th IFToMM World Congress, Taipei, Taiwan, 25-30 October 2015. [CrossRef]

25. Saulescu, R.; Neagoe, M.; Jaliu, C. Improving the Energy Performance of Wind Turbines Implemented in the Built Environment Using Counter-Rotating Planetary Transmissions. IOP Conf. Ser. Mater. Sci. Eng. 2016, 147, 012089. [CrossRef]

26. Saulescu, R.; Jaliu, C.; Neagoe, M. Structural and Kinematic Features of a 2 DOF Speed Increaser for Renewable Energy Systems. Appl. Mech. Mater. 2016, 823, 367-372. [CrossRef]

27. Saulescu, R.; Neagoe, M.; Jaliu, C.; Munteanu, O. Comparative Analysis of Two Wind Turbines with Planetary Speed Increaser in Steady-State. Appl. Mech. Mater. 2016, 823, 355-360. [CrossRef]

28. Saulescu, R.; Jaliu, C.; Munteanu, O.; Climescu, O. Planetary Gear for Counter-Rotating Wind Turbines. Appl. Mech. Mater. 2014, 658, 135-140. [CrossRef]

29. Saulescu, R.; Jaliu, C.; Climescu, O.; Diaconescu, D. On the use of 2 DOF planetary gears as "speed increaser" in small hydros and wind turbines. In Proceedings of the ASME International Design Engineering Technical Conferences \& Computers and Information in Engineering Conference IDETC/CIE 2011, Washington, DC, USA, 25-31 August 2011.

30. Herzog, R.; Schaffarczyk, A.P.; Wacinski, A.; Zürcher, O. Performance and stability of a counter-rotating windmill using a planetary gearing: Measurements and Simulation. In Proceedings of the European Wind Energy Conference \& Exhibition, Warsaw, Poland, 20-23 April 2010.

31. Neagoe, M.; Saulescu, R.; Jaliu, C. Design and Simulation of a 1 DOF Planetary Speed Increaser for Counter-Rotating Wind Turbines with Counter-Rotating Electric Generators. Energies 2019, 12, 1754. [CrossRef]

32. Saulescu, R.; Neagoe, M.; Jaliu, C. Conceptual Synthesis of Speed Increasers for Wind Turbine Conversion Systems. Energies 2018, 11, 2257. [CrossRef]

33. Neagoe, M.; Jaliu, C.; Saulescu, R.; Simionescu, P. Steady-State Response of a Dual-Rotor Wind Turbine with Counter-Rotating Electric Generator and Planetary Gear Increaser. In Proceedings of the USCToMM MSR 2020, Rapid City, SD, USA, 14-16 May 2020; pp. 106-115. [CrossRef]

34. Zhao, M.; Ji, J. Dynamic Analysis of Wind Turbine Gearbox Components. Energies 2016, 9, 110. [CrossRef]

35. Dong, H.; Zhang, C.; Wang, D.; Xu, S.; Qiu, J. Dynamic characteristics of gear box with PGT for wind turbine. Procedia Comput. Sci. 2017, 109, 801-808. [CrossRef]

36. Vázquez-Hernández, C.; Serrano-González, J.; Centeno, G. A Market-Based Analysis on the Main Characteristics of Gearboxes Used in Onshore Wind Turbines. Energies 2017, 10, 1686. [CrossRef]

37. Farahani, E.; Hosseinzadeh, N.; Ektesabi, M. Comparison of fault-ride-through capability of dual and single-rotor wind turbines. Renew. Energy 2012, 48, 473-481. [CrossRef]

38. Kutt, F.; Blecharz, K.; Karkosiński, D. Axial-Flux Permanent-Magnet Dual-Rotor Generator for a Counter-Rotating Wind Turbine. Energies 2020, 13, 2833. [CrossRef]

39. Mirnikjoo, S.; Abbaszadeh, K.; Abdollahi, S.E. Multi-Objective Design Optimization of a Double-Sided Flux Switching Permanent Magnet Generator for Counter-Rotating Wind Turbine Applications. IEEE Trans. Ind. Electron. 2020, 1. [CrossRef]

40. Zhamalov, A.Z.; Obozov, A.D.; Kunelbaev, M.M.; Baikadamova, L.S. Capacity and Power Characteristics of Disk Generator with Counter-Rotation of Double-Rotor Wind Turbine. Middle-East J. Sci. Res. 2013, 15, 1655-1662. [CrossRef]

41. Kanemoto, T.; Galal, A.M. Development of Intelligent Wind Turbine Generator with Tandem Wind Rotors and Double Rotational Armatures. JSME Int. J. Ser. B 2006, 49, 450-457. [CrossRef]

42. Caiozza, J. Wind Driven Electric Generator Apparatus. U.S. Patent 7,227,276 B2, 5 June 2007.

43. Pacholczyk, M.; Karkosiński, D. Parametric Study on a Performance of a Small Counter-Rotating Wind Turbine. Energies 2020, 13, 3880. [CrossRef]

44. Saulescu, R.; Neagoe, M.; Cretescu, N. Comparative analysis of two wind turbines with counter-rotating vs. fixed-stator electric generator. IOP Conf. Ser. Mater. Sci. Eng. 2020, 997, 012091. [CrossRef]

45. Fan, G.-F.; Qing, S.; Wang, H.; Hong, W.-C.; Li, H.-J. Support Vector Regression Model Based on Empirical Mode Decomposition and Auto Regression for Electric Load Forecasting. Energies 2013, 6, 1887-1901. [CrossRef]

46. Hong, W.-C.; Fan, G.-F. Hybrid Empirical Mode Decomposition with Support Vector Regression Model for Short Term Load Forecasting. Energies 2019, 12, 1093. [CrossRef]

47. Pfaffel, S.; Faulstich, S.; Rohrig, K. Performance and Reliability of Wind Turbines: A Review. Energies 2017, 10, 1904. [CrossRef]

48. Neagoe, M.; Saulescu, R.; Jaliu, C.; Simionescu, P.A. A Generalized Approach to the Steady-State Efficiency Analysis of TorqueAdding Transmissions Used in Renewable Energy Systems. Energies 2020, 13, 4568. [CrossRef]

49. Miloiu, G.; Dudita, F.; Diaconescu, D. Modern Mechanical Transmissions; Tehnica: Bucharest, Romania, 1980. (In Romanian) 